\title{
Ecotoxicity of Purified Industrial Waste Water
}

\author{
Mariyana Lyubenova ${ }^{1}$, Snejana Dineva ${ }^{2, *}$, Kristiana Cala $^{1}$, Branislav Dinich $^{1}$, Silvena Boteva $^{1}$ \\ ${ }^{1}$ Faculty of Biology, University of Sofia, 8 D. Tsankov Blvd., Bulgaria \\ ${ }^{2}$ Faculty of Techniques and Technology, Trakia University, Stara Zagora, Yambol 8602, "Gr. Ignatiev" str. №38, Bulgaria
}

Copyright $\bigcirc 2019$ by authors, all rights reserved. Authors agree that this article remains permanently open access under the terms of the Creative Commons Attribution License 4.0 International License

\begin{abstract}
Purified industrial waste water (PIWW) has been evaluated for probable toxicity using test-systems with Pseudorasbora parva (topmouth gudgeon) and Lepidium sativum L (garden cress). The acute toxicity of PIWW was calculated according to mortality of Pseudorasbora parva in dilutions 1, 5, 10, 25, 50, 100 and 200 times, and distillate water (DW) was used as a control. The $\mathrm{LC}_{50}$ has been calculated after $96 \mathrm{~h}$ of treatment and it was at approximately $8 \times$ (7.69) times dilution of PIWW. The toxic effect of PIWW with and without copper ions, added as $\mathrm{CuSO}_{4}$ have been measured using Lepidium sativum $\mathrm{L}$. The comparison of the toxic effects of the same concentrations of copper in PIWW and DW, mixed and non-mixed contamination has been evaluated. It was found that $\mathrm{Cu}^{+2}$ has inhibitory effects on the root's and stem's growth of Lepidium sativum L seeds, and that effect appears in concentrations over $2 \mathrm{mg} / 1 \mathrm{Cu}^{+2}$. The $50 \%$ inhibition of root's growth in DW was $E_{50}=7.26 \mathrm{mg} / \mathrm{l}$ of copper ions, while for PIWW that concentration was $\mathrm{EC}_{50}$ $=17.23 \mathrm{mg} / \mathrm{l} \mathrm{Cu}^{+2}$. The calculated $\mathrm{EC}_{50}$ for stem's growing in DW was $54.57 \mathrm{mg} / \mathrm{l} \mathrm{Cu}^{+2}$ and $72.07 \mathrm{mg} / \mathrm{C} \mathrm{Cu}^{+2}$ in PIWW. The observed $\mathrm{EC}_{50}$ differences in DW and PIWW perhaps are due to the formation of ligand compounds among copper cations and other impurities in the waste water and hence as consequences the reducing of free $\mathrm{Cu}^{+2}$ or their bioavailability, hereafter reduce copper toxicity. It was registered that PIWW diminished growth inhibitory effect of copper ions on Lepidium sativum $\mathrm{L}$ seeds lessening its amount by involving free $\mathrm{Cu}^{+2}$ in complexes with other waste products.
\end{abstract}

Keywords $\quad \mathrm{LC}_{50}, \mathrm{EC}_{50}$, Copper Ions, Purified Industrial Waste Water, Lepidium sativum L., Pseudorasbora parva

\section{Introduction}

Heavy metals are naturally occurring elements and significant environmental pollutants; their toxicity is a crucial problem with increasing ecological, nutritional and environmental importance, especially in regions with pronounced anthropogenic pressure $[40,61,4,8,15$, and 19]. The Environmental Quality Standards (EQSs) for freshwater are based on laboratory experiments that are often carried out with inorganic metal salts, where the ions are more bioavailable [10]. It is well-known that the bioavailability of metals is significantly influenced by $\mathrm{pH}$, alkalinity and hardness of water, and differs for each metal and its speciation [19]. The bioavailability of ions was recognized as a key factor when setting EQSs for metals $[10,19]$. The differences in the bioavailability of metals in laboratory tests compared to field situation are a crucial topic when the risk levels are projected $[10,19]$. Conversion of the metal ions toxicity effects to the field situation is a hard task, where metals are incorporated in complexes with dissolved organic matter (DOM) and other components of the system [10]. Even acute concentration of different toxicant differs with its speciation and with environmental conditions [45]. In the conversion of the toxicity often water $\mathrm{pH}$ is not taken into account; though there is clear evidence that just $\mathrm{pH}$ can greatly modify the toxicity of the pollutants [31]. Ordinary chronic toxicity is much less affected by hardness of water than the acute [19, 22]. For instance, in case of $\mathrm{Cu}^{+2}$ the water hardness did not affect chronic toxicity to Daphnia, but affected acute toxicity [22]. $\mathrm{Cu}^{+2}$ are acutely lethal to freshwater fish in soft water at low concentrations ranging from $10-20 \mathrm{ppb}$ [41]. Oronsaye and Ogbebo (1997) reported $L^{2} C_{50}$ of $0.4 \mathrm{mg} / \mathrm{l}$ for Clarias gariepinus exposed to 96 hour of copper sulphate in soft water [47].

Copper is an essential trace element, naturally occurs in the aquatic environment in low concentrations and serves as a minor nutrient for plants and animals $[16,19,66]$, but in higher concentrations is an actually toxic for aquatic life $[16,19,26]$. Major U.S. aquifers have $\mathrm{Cu}^{+2}$ concentrations less than $10 \mathrm{ppb}$ [36], Canadian freshwaters $1-8 \mathrm{ppb} \mathrm{Cu}^{+2}$ [6], streams in Bristol Bay $0.04-5.60 \mathrm{ppb} \mathrm{Cu}^{+2}$ [67], and for seawater copper concentrations are recorded generally less than $1 \mathrm{ppb}$ [42]. Copper is a toxic metal to aquatic organisms and ecosystems, and has effects on fish, invertebrates, and amphibians; which are equally sensitive to chronic toxicity [62,32, and 57]. Copper in the lake is 
bioavailable and bioaccumulate by organisms up to high levels in many different organs and some effects of long-term toxicity of copper on benthic community and planktonic biomass were pointed out $[12,63]$. Copper is moderately soluble in water and binds easily to sediments and organic matter [16], and does not biomagnify in food webs [16, 57]. However, there is evidence of biomagnification of copper in the food chain with possible threats to human health noticed in the case study of grossly polluted Korle Lagoon [12]. Although, mammals are not so sensitive to copper toxicity as aquatic organisms, biomagnifications play a critical role in the poisoning. Toxicity in mammals include a wide range of animals and effects, such as liver cirrhosis, kidneys and brain necrosis, gastrointestinal distress, lesions, low blood pressure and fetal mortality $[6,34,64,65]$.

Aquatic habitats are susceptible for pollution because they are ultimate receptor of industrial and urban wastewater, storm water runoff, and atmospheric deposition [21, 43]. Oyewo [48] tested some metals found in the industrial effluents on five animal species: Cypris sp., Mugil sp., Tilapia sp., Nerita senegalensis, and Clibanarius africanus that normally inhabit the Lagos Lagoon. The values on the general order of toxicity of the test metals were: $\mathrm{Hg}, \mathrm{Cu}, \mathrm{Mn}$, and $\mathrm{Fe}$, when they were tested separately. Elevated aquatic $\mathrm{Cu}^{+2}$ concentrations are primarily occurring near copper mining, smelting facilities and in urbanized areas $[21,25]$. Higher $\mathrm{Cu}^{+2}$ concentrations are observed in mine-impacted Mineral Creek Colorado, where they were approximately $410 \mathrm{ppb}$ [55] and around the mine impacted Copperas Brook in Vermont where they were around $4600 \mathrm{ppb}$ [8]. Sansalone et al. [56] documented $\mathrm{Cu}^{+2}$ concentrations of $325 \mathrm{ppb}$ in urban storm water run-off, such copper concentrations are lethal to fish and aquatic life [25].

The anthropogenic contamination of water involves dissolved heavy metals, detergents, DOM, etc. Low levels of detergents increase the uptake of other pollutants [1]. For instance, the mixture of anionic detergents and $\mathrm{Cu}^{+2}$ causes toxic effect "more-than-additive", while the mixture of non-anionic detergent and metal ions produces toxic effect that is probably "less-than-additive" on rainbow trout [15].

The waste water mixers frequently contain detergents with high portion of phosphorus causing eutrophication [12, 50]. It has been reported that the presence of $1 \mathrm{mg} / 1$ detergents in water causes plankton perishes; $3 \mathrm{mg} / \mathrm{l}$ - mass Daphne death; $5 \mathrm{mg} / 1$ - fish damage [38]. In concentrations between 0.4 and $40 \mathrm{mg} / 1$ synthetic detergents are reported to be acutely toxic to fish [1]. Invertebrates, especially in their juvenile stages, are extremely sensitive to detergents in concentration below $0.1 \mathrm{mg} / \mathrm{l}$. The detergents are very hazardous among the pollutants, particularly for the water organisms, they can form a layer of foam on the water surface with considerable thickness and to prevent oxygen exchange of the aqua ecosystems with all resulting consequences. Contaminated water containing detergents can hardly be purified by biochemical oxidation [39]. In many countries there are no legislations to control phosphates in soaps. In Canada phosphate-laden dish detergents are banned for sale from 2010; numerous USA municipalities banned the phosphate both in detergents and fertilizers in an effort to minimize the runoff [50].

The aim of this study is to evaluate the toxic effect of PIWW with and without higher copper concentration; and to compare the effects of the same concentrations of copper in purified waste water and distilled water.

\section{Materials and Methods}

\subsection{Sofia Med Company}

SOFIA MED S.A. is a manufacturer of a wide range of rolled and extruded products made of copper, copper alloy and zinc, such as sheets, strips, plates, discs, bars, rods, profiles, wires, which find various applications. The Sofia Med S.A. is a part of Halcor Group that manufactures metal products of copper and brass tubes, copper, zinc and brass rolled and extruded products, as well as cables. Halcor Group consists of 13 companies in 6 countries (Greece, Bulgaria, Romania, United Kingdom, France and Germany) and runs 10 plants in Greece, Bulgaria and Romania.

The Sofia Med S.A. is located in the eastern part of Sofia, Bulgaria (www.sofiamed.bg/bg). The company is engaged in the manufacture of copper, brass and titan zinc rolled products as well as copper extruded products. The company produced sheets, strips, plates, discs, bars, rods, profiles, copper and brass pipes, power and telecommunication cables, wires, etc., made of copper, copper alloy and zinc. The plant has three production workshops: foundry, rolling and extrusion workshops.

The purified industrial waste water (PIWW) of Sofia Med Company contained unsolved substances, sulphate ions, petroleum products, copper, lead, zinc, detergents and dissolved organic matter (DOM). The PIWW of the company contained soap that is used to remove oil entering during the production process. The maximum allowable toxicant concentrations (MATC) in waste water of Sofia Med Company are represented in table 1.

Table 1. Emission norms of waste water pollutant from Sofia Med Company Purification Station

\begin{tabular}{|l|c|}
\hline \multicolumn{1}{|c|}{ Parameters } & $\begin{array}{c}\text { Maximum allowable toxicant } \\
\text { concentrations (MATC) - mg// }\end{array}$ \\
\hline Active Reaction $\mathbf{( p H )}$ & $6.5-9.0$ \\
\hline Unsolved substances, $\mathbf{m g} / \mathbf{l}$ & 400 \\
\hline Sulphate ions, $\mathbf{~ m g / l}$ & 400 \\
\hline Petroleum products, $\mathbf{m g} / \mathbf{l}$ & 15 \\
\hline Copper, $\mathbf{m g} / \mathbf{l}$ & 2.0 \\
\hline Lead, $\mathbf{m g} / \mathbf{l}$ & 2.0 \\
\hline Zinc, $\mathbf{m g} / \mathbf{l}$ & 5.0 \\
\hline
\end{tabular}


Sofia Med S.A. operates in accordance with rigorous management systems for quality, environmental protection, occupational health and safety, as well as in accordance with ISO 9001, ISO 14001 and OHSAS 18001 [53]. The company uses private water-supply and drinking water. A safety level of $\mathrm{Cu}^{2+}$ in drinking water is accepted to be less than $2.0 \mathrm{mg} / \mathrm{l}$, according to EU and government legislation [24]. The purified industrial waste water (PIWW) from the company is discharged into the Iskar River.

\subsection{Description of the Conducted Tests for Evaluation of Purified Waste Water Toxicity}

\subsubsection{Acute Toxicity of Purified Waste Water - Biotest with Pseudorasbora parva (Topmouth Gudgeon)}

The acute toxicity of purified waste water was tested with Pseudorasbora parva. The conditions were kept optimal for the development of fish according to ISO 7346 [39]. In the conducted experiment the temperature was constant $24^{\circ} \mathrm{C} ; \mathrm{O}_{2}=8-9 \mathrm{mg} / \mathrm{l} ; \mathrm{pH}$ varied in the samples (table 3) with different dilution of PIWW, and different toxicant concentrations (table 1).

Dilutions of PIWW used in the experiments: original PIWW $=1 \mathrm{x}, 5 \mathrm{x}, 10 \mathrm{x}, 25 \mathrm{x}, 50 \mathrm{x}, 100 \mathrm{x}$ and 200x times, and distilled water (DW) as a control, in total 8 variants of testing. In 8 test boxes out of 21, survival of 7 fishes for every variant of testing was observed after 96 hours. The results are presented as a percentage of mortality with reference to the control and as probit units (PU) of the percentage of mortality in different dilutions.

The dilution of PIWW causing a 50\% mortality in Pseudorasbora parva in $96 \mathrm{~h}$ was recorded.

\subsubsection{Biotest with Lepidium sativum L (Garden Cress)}

The biotest with Lepidium sativum L. was used to assess water toxicity. The tests were carried out on a solid substrate in pots, on floating hydrocracker stands and in petri dishes with soaked filter paper. The high sensitivity of plants at this early stage of development is very appropriate to assess the toxic effects (ISO 7346, [39]). The test is based on the high sensitivity of plants at this early stage of development, to the level of toxicants.

The preliminary preparation of the tests included:

A. Preparing the variants: Control distilled water (DW); DW CU ${ }^{+2}$ mg..$^{-1}$; Original waste water (WW) with 2 mg. $1^{-1} \mathrm{Cu}$ and other impurities; next tested concentrations were with $\mathrm{DW}+5,25,50,75,125$ and $250 \mathrm{mg} / \mathrm{l} \mathrm{Cu}^{2+}$ (fig.1 a) and $\mathrm{WW}+5,25,50,75,125$ and $250 \mathrm{mg} / \mathrm{C} \mathrm{Cu}^{2+}$ (fig. $1 \mathrm{~b}$ ).

B. Preparing the Petri dishes: 3 plates were prepared for every variant of testing. After sterilizing the petri dishes (with cotton and alcohol) and filter papers (autoclaved under dry steam for 30 minutes at 1 atm and $121^{\circ} \mathrm{C}$ ), the double-layer filter paper on the base of the plate was soaked in $10 \mathrm{ml}$ of DW (control) or $10 \mathrm{ml}$ of corresponding solution in different variants. The filter paper on the lid of the plate was soaked in $5 \mathrm{ml} \mathrm{DW}$ for the control or in solutions with different $\mathrm{CuSO}_{4}$ concentrations.

C. Preparing the biotest: seeds were kept in a refrigerator for 24 hours [14], then they were soaked in the distilled water for 24 hours; 50 identical seeds were arranged at equal distances on the moistened paper on the base, and loaded plates were closed.

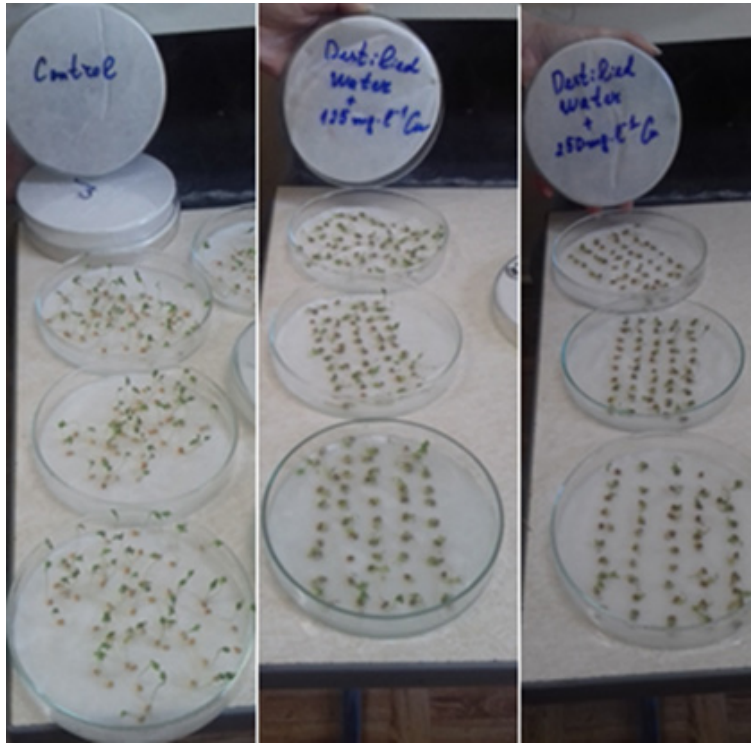

(a) in DW
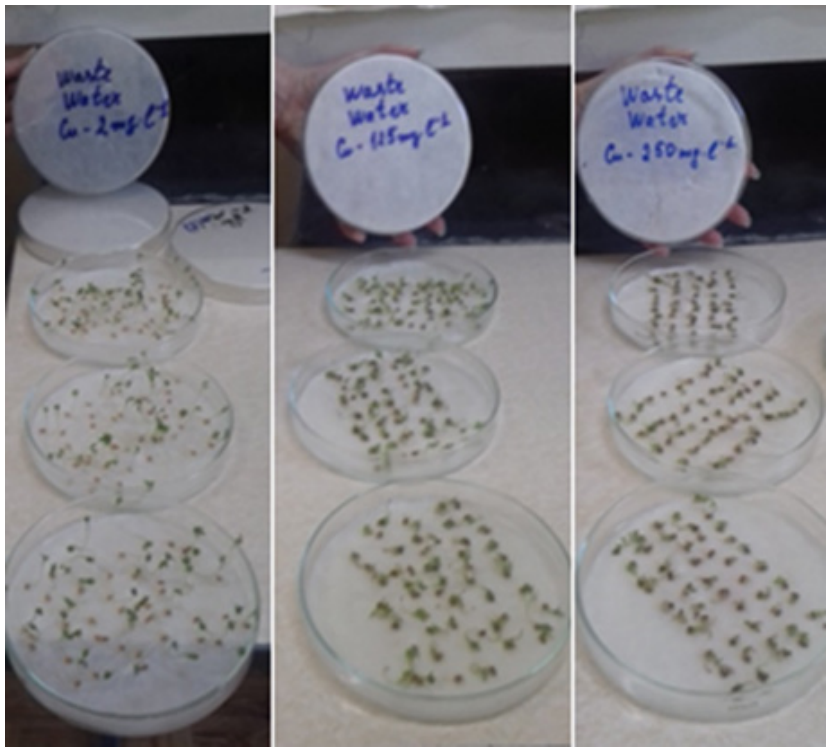

(b) in PIWW

Figure 1. The Lepidium sativum L. seeds after three-day exposure to different concentrations of $\mathrm{Cu}^{+2}$ ions: (a) in DW; (b) in PWW 
The $\mathrm{pH}$ and temperatures of water by variants were measured using $\mathrm{pH}$-meter HANNA. The laboratory tests were conducted at room temperature $18-20^{\circ} \mathrm{C}$. After $96 \mathrm{~h}$ the length of the stems and roots were measured in $\mathrm{mm}$. The measured indicator is sensitive to the pollution and other environmental factors that influenced seed's growth [39].

\subsection{Statistical Analysis}

\subsubsection{Probit Analysis}

Probit Analysis is commonly used in toxicology to determine the relative toxicity of chemicals to living organisms [35]. Probit analysis is a specialized regression model of binomial response (e.g. death/no death) variables [44], and the relationship between the response and the various concentrations is always sigmoid [35, 23]. Probit analysis acts as a transformation from sigmoid to linear and then runs a regression on the relationship [35, 44].

Determination of probit units (PU) and evaluation of $\mathrm{LC}_{50}$ can be easily done using the Finney's table (table 2), for converting $\%$ mortality to probits.

Table 2. Finney's table for converting \% mortality to probit [29]

\begin{tabular}{l|c|c|c|c|c|c|c|c|c|c}
\hline $\boldsymbol{\%}$ & $\mathbf{0}$ & $\mathbf{1}$ & $\mathbf{2}$ & $\mathbf{3}$ & $\mathbf{4}$ & $\mathbf{5}$ & $\mathbf{6}$ & $\mathbf{7}$ & $\mathbf{8}$ & $\mathbf{9}$ \\
\hline $\mathbf{0}$ & - & 2.67 & 2.95 & 3.12 & 3.25 & 3.36 & 3.45 & 3.52 & 3.59 & 3.66 \\
10 & 3.72 & 3.77 & 3.82 & 3.87 & 3.92 & 3.96 & 4.01 & 4.05 & 4.08 & 4.12 \\
20 & 4.16 & 4.19 & 4.23 & 4.26 & 4.29 & 4.33 & 4.36 & 4.39 & 4.42 & 4.45 \\
30 & 4.48 & 4.50 & 4.53 & 4.56 & 4.59 & 4.61 & 4.64 & 4.67 & 4.69 & 4.72 \\
\hline 40 & 4.75 & 4.77 & 4.80 & 4.82 & 4.85 & 4.87 & 4.90 & 4.92 & 4.95 & 4.97 \\
50 & 5.00 & 5.03 & 5.05 & 5.08 & 5.10 & 5.13 & 5.15 & 5.18 & 5.20 & 5.23 \\
60 & 5.25 & 5.28 & 5.31 & 5.33 & 5.36 & 5.39 & 5.41 & 5.44 & 5.47 & 5.5 \\
70 & 5.52 & 5.55 & 5.58 & 5.61 & 5.64 & 5.67 & 5.71 & 5.74 & 5.77 & 5.81 \\
80 & 5.84 & 5.88 & 5.92 & 5.95 & 5.99 & 6.04 & 6.08 & 6.13 & 6.18 & 6.23 \\
90 & 6.28 & 6.34 & 6.41 & 6.48 & 6.55 & 6.64 & 6.75 & 6.88 & 7.05 & 7.33 \\
- & 0.0 & 0.1 & 0.2 & 0.3 & 0.4 & 0.5 & 0.6 & 0.7 & 0.8 & 0.9 \\
\hline 99 & 7.33 & 7.37 & 7.41 & 7.46 & 7.51 & 7.58 & 7.65 & 7.75 & 7.88 & 8.09 \\
\hline
\end{tabular}

For instance, for a $17 \%$ death response, the corresponding probit would be 4.05 ; for a $15 \%$, the PU would be 3.96 ; for $20 \%$ dead response the probit would be 4.16 . Furthermore, for a $50 \%$ response $\left(\mathrm{LC}_{50}\right)$, the corresponding probit would be 5.00 .

The results were statistically processed.

\subsection{Growth Test Inhibition (GrInh \%)}

The growth inhibitory effect (GrInh \%) of different concentrations of $\mathrm{Cu}^{+2}$ ions, added as $\mathrm{CuSO}_{4}$ salt, has been evaluated in DW and in PWW on Lepidium sativum L seeds. The percentage of the mean for every variant values with reference to the control $(100 \%)$ was calculated. The growth inhibition (GrInh \%) of used concentrations was calculated by the formula:

$$
\text { Gr Inh } \%=\frac{\text { Gr control }- \text { Gr sample }}{\text { Gr control }} .100
$$

$\mathrm{EC}_{50}$ of growth inhibition (GrInh \%) for different variants were evaluated.

One-way ANOVA was performed using Statistic 7.0 software (Stat soft; www.statsoft.com) to compare the means of different treatments in each of the tests. The significance level was set at 0.05 .

All results given in \% were graphically represented and $\mathrm{EC}_{50}$ approximate value was calculated [3].

\section{Results}

\subsection{Toxicity Identification Evaluations (TIEs) with Pseudoraspora parva}

Acute ecotoxicological test examinations are the first step to detect the total toxic effects caused by toxicant, and virtually every hydrobiont is suitable for conducting the tests [38]. The assessment of the environmental risk values helped to determine whether the toxicant is biologically active at test doses and to define $\mathrm{LC}_{50}$, which proved to be lethal causing death to $50 \%$ of the tested organisms [44]. 
The toxic effects of purified industrial waste water (PIWW) have been evaluated on the topmouth gudgeon (Pseudoraspora parva) as a \% of mortality after $96 \mathrm{~h}$ exposure to different dilutions of PIWW (table 3 ).

Table 3. Toxic effects of purified waste water on Pseudoraspora parva

\begin{tabular}{|c|c|c|c|c|}
\hline Dilution of PWW & $\mathbf{p H}\left(\mathbf{t}=\mathbf{2 4}{ }^{\circ} \mathbf{C}\right)$ & Mortality (n) & Mortality $\%$ & PU \\
\hline Control - DW & 6,74 & 0 & 0.00 & 0.00 \\
\hline $200 \mathrm{x}$ & 6,74 & 0 & 0.00 & 0.00 \\
\hline $100 \mathrm{x}$ & 6,84 & 0 & 0.00 & 0.00 \\
\hline $50 \mathrm{x}$ & 6,97 & 2 & 28.57 & 4.42 \\
\hline $25 \mathrm{x}$ & 7,19 & 3 & 42.86 & 4.82 \\
\hline $10 \mathrm{x}$ & 7,42 & 3 & 42.86 & 4.82 \\
\hline $5 \mathrm{x}$ & 7,58 & 5 & 71.43 & 5.55 \\
\hline $1 \mathrm{x}$ & 7,52 & 7 & 100.00 & 8.09 \\
\hline
\end{tabular}

Dilutions of purified waste water: $1 \mathrm{x}, 5 \mathrm{x}, 10 \mathrm{x}, 25 \mathrm{x}, 50 \mathrm{x}, 100 \mathrm{x}$ and 200x times or in opposite order $0.005,0.01,0.02$, $0.04,0.1,0.2$ and 1 (undiluted PIWW); distillated water (DW) was used as control. The temperature was $24^{\circ} \mathrm{C}$, kept constant during the experiment. In undiluted PIWW after $96 \mathrm{~h}$ was registered $100 \%$ mortality, all fishes were died. The equation that maximum fitted to the obtained results was logarithmic $\mathrm{f}(\mathrm{x})=-19.4258492121 \ln (\mathrm{x})+98.945$ with correlation coefficient $\mathrm{R}^{2}=0.959 .50 \%$ of mortality, $\mathrm{LC}_{50}$, was detected in a range between 5 and 10 times dilutions of PIWW, and in 0.2 and 0.1 dilutions of PIWW with $71.43 \%$ and $42.86 \%$ mortality, respectively.

The probit-log concentration graph is considered as an excellent way for calculation of $\mathrm{LC}_{50}$ and toxicity result presentation [44]. The percentage of mortality was converted into Probit Units (PU) using the Finney's table (table 2). The results are presented in table 3 and fig.2. The concentration leading to $50 \%$ mortality after $96 \mathrm{~h},\left(\mathrm{LC}_{50}\right)$, was calculated using the equation $\mathrm{y}=3.566 * \mathrm{x}+4.535$ of linear regression (fig. $2 \mathrm{a}$ ).

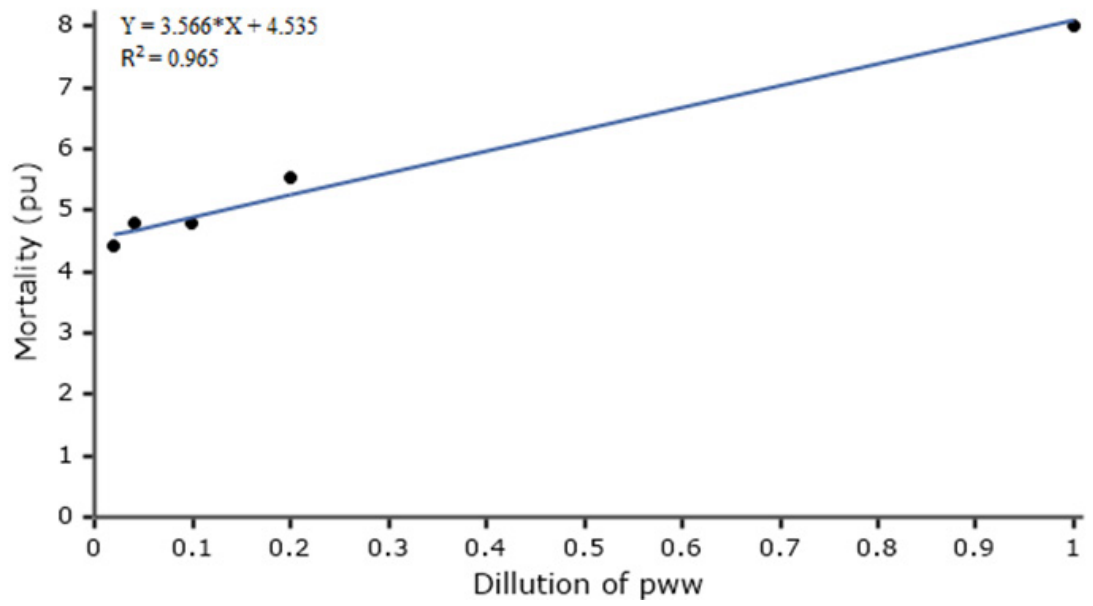

(a) Toxic effect - PU depending of PIWW dilution $($ Residual Variance $=0.002 ; \mathrm{F}($ Fisher $)=83.057 ; \mathrm{p}<0.0028)$

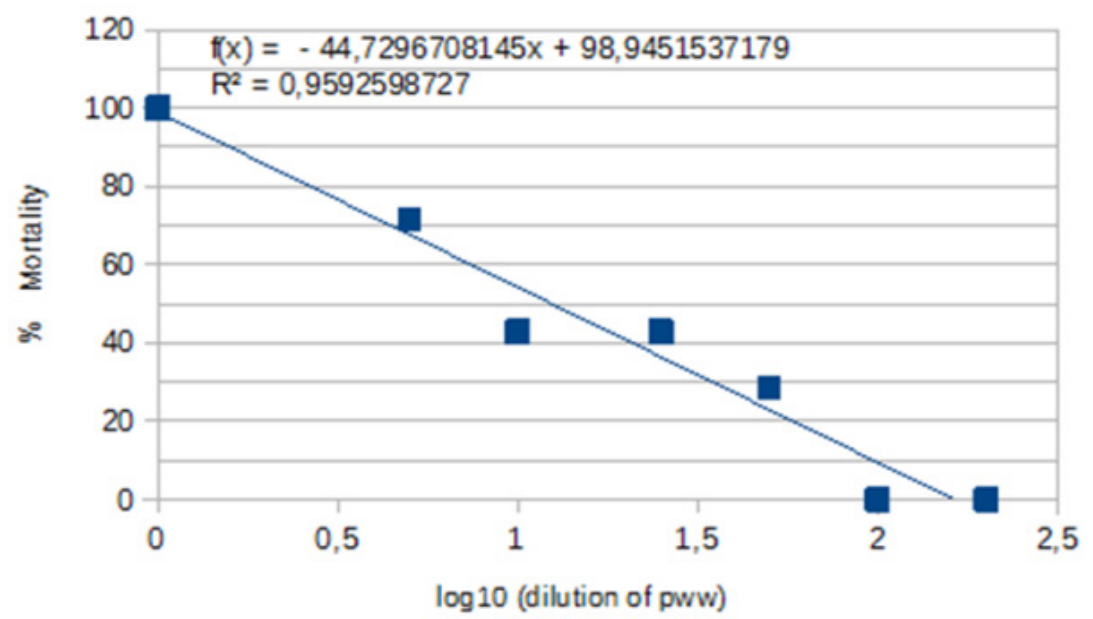

(b) Toxic effect as \% mortality of Pseudoraspora parva

Figure 2. Toxic effect of purified waste water on Pseudoraspora parva 
The regression correlated well with the observed data with coefficient $R^{2}=0.965$. The Equation $\mathrm{Y}=\mathrm{b} 1 * \mathrm{X}+\mathrm{b} 0$, has b0 $=4.535 \pm 0.381$ with C.I. $(95 \%)$ and for b1 (slope) $=3.566 \pm 1.245$ with C.I. (95\%). The above equation showed calculated $\mathrm{LC}_{50}$ to occur at 0.13 PIWW dilutions, approximately $8 \mathrm{x}(7.69)$ times purified waste water dilution lead to $50 \%$ mortality of Pseudoraspora parva.

The calculated $\mathrm{LC}_{50}$ based on the linear regression of mortality (\%) to logarithmic dilution of PIWW (Fig.3b) obtained result $8 \mathrm{x}$ (7.82) times dilution of PIWW for $50 \%$ mortality of Pseudoraspora parva, with $\mathrm{R}^{2}=0.959$.

Therefore, $\mathrm{LC}_{50}$ toxic effect appears in dilution of PIWW less than 10 times.

\subsection{Biotests with Lepidium Sativum $\mathbf{L}$}

Lepidium sativum $\mathrm{L}$ (garden cress) is a sensitive plant used as a toxicity tests object, because of its rapid growth, low cost and easy analyses [51]. The $\mathrm{Cu}^{+2}$ growth inhibitory effect (GrInh \%) has been assessed in DW and PIWW on Lepidium sativum $\mathrm{L}$ seeds. The obtained results are represented in Table 4 and Fig.3.

Table 4. Lepidium sativum $L$ growth inhibition

\begin{tabular}{|c|c|c|c|c|c|}
\hline \multicolumn{6}{|c|}{ Growth inhibition of roots $(\%)$} \\
\hline \multirow[b]{2}{*}{$\mathrm{Cu}^{2+}(\mathrm{mg} / \mathrm{l})$} & \multicolumn{2}{|c|}{ DW } & \multicolumn{2}{|c|}{ PWW } & \multirow{2}{*}{$\begin{array}{c}\text { Gr Inh \% } \\
\text { (PIWW-DW) }\end{array}$} \\
\hline & $\begin{array}{c}\text { Root's length, }(\mathrm{mm}) \\
\text { mean } \pm \text { C.I. }\end{array}$ & Gr Inh \% & $\begin{array}{l}\text { Root's length, } \\
\text { mean } \pm \text { C.I. }(\mathrm{mm})\end{array}$ & Gr Inh\% & \\
\hline $\mathrm{DW}+0$ & $65.89 \pm 3.26$ & & & & \\
\hline 2 & $58.02 \pm 3.64$ & 11.94 & $74.91 \pm 5.21$ & -13.70 & -25.64 \\
\hline 10 & $19.87 \pm 2.41$ & 69.84 & $44.7 \pm 2.62$ & 32.16 & -37.68 \\
\hline 25 & $10.56 \pm 2.14$ & 83.97 & $20.3 \pm 2.75$ & 69.19 & -14.78 \\
\hline 50 & $4.69 \pm 1.29$ & 92.88 & $11.53 \pm 8.02$ & 82.50 & -10.38 \\
\hline 75 & $3.03 \pm 0.96$ & 95.4 & $4.66 \pm 1.08$ & 92.93 & -2.47 \\
\hline 125 & $2.54 \pm 0.75$ & 96.14 & $3.41 \pm 0.64$ & 94.82 & -1.32 \\
\hline 250 & $1.83 \pm 0.26$ & 97.22 & $2.07 \pm 0.27$ & 96.86 & -0.36 \\
\hline \multicolumn{6}{|c|}{ Growth inhibition of stems (\%) } \\
\hline \multirow[b]{2}{*}{$\mathrm{Cu}^{2+}(\mathrm{mg} / \mathrm{l})$} & \multicolumn{2}{|c|}{ DW } & \multicolumn{2}{|c|}{ PWW } & \\
\hline & $\begin{array}{l}\text { Stem's length, } \\
(\mathrm{mm}) \text { mean } \pm \text { C.I }\end{array}$ & Gr Inh \% & $\begin{array}{l}\text { Stem's length, } \\
(\mathrm{mm}) \text { mean } \pm \text { SD }\end{array}$ & Gr Inh \% & $\begin{array}{c}\text { Gr Inh \% } \\
\text { (PIWW-DW) }\end{array}$ \\
\hline $\mathrm{DW}+0$ & $23.29 \pm 1.12$ & & & & \\
\hline 2 & $20.17 \pm 0.74$ & 13.37 & $28.48 \pm 0.54$ & -22.29 & -35.66 \\
\hline 10 & $22.71 \pm 1.22$ & 2.48 & $21.16 \pm 0.79$ & 9,13 & 6.65 \\
\hline 25 & $17.09 \pm 1.26$ & 26.59 & $24.09 \pm 1.23$ & $-3,466$ & -30.056 \\
\hline 50 & $12.23 \pm 0.66$ & 47.48 & $21.16 \pm 1.05$ & 9,13 & -38.35 \\
\hline 75 & $9.02 \pm 1.24$ & 61.26 & $10.38 \pm 1.38$ & 55,42 & -5.84 \\
\hline 125 & $9.48 \pm 1.1$ & 59.29 & $10.49 \pm 0.82$ & 54,94 & -4.35 \\
\hline 250 & $4.93 \pm 0.48$ & 78.81 & $4.15 \pm 0.34$ & 82,16 & 3.35 \\
\hline
\end{tabular}

Observed differences of growth depending of water source (DW or PWW)

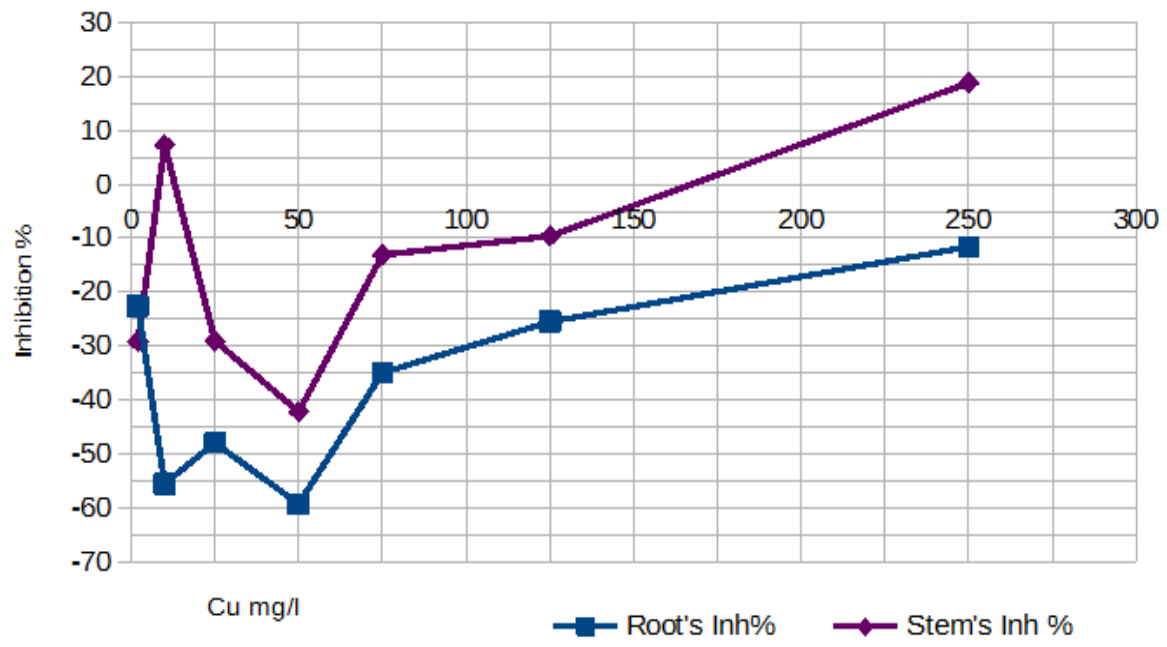

Figure 3. Reduced inhibitory effect of $\mathrm{Cu}^{+2}$ in PWW ( $\left.\mathrm{Gr} \mathrm{Inh}_{\mathrm{PWw}}-\mathrm{Gr} \mathrm{Inh}_{\mathrm{DW}}\right) \%$ 
It has been found that $\mathrm{Cu}^{+2}$ have inhibitory effect on the root's and stem's growth of Lepidium sativum L seeds, and it appears in concentration over $2 \mathrm{mg} / 1$ (Table 4; Fig.4 and 5). Also the combination of $\mathrm{Cu}^{+2}$ and PIWW led to reduced toxicity, and respectively, decreased inhibitory effect of the copper ions (Table 4, Fig. 3), that resulted in stimulation of root's and stem's growth.
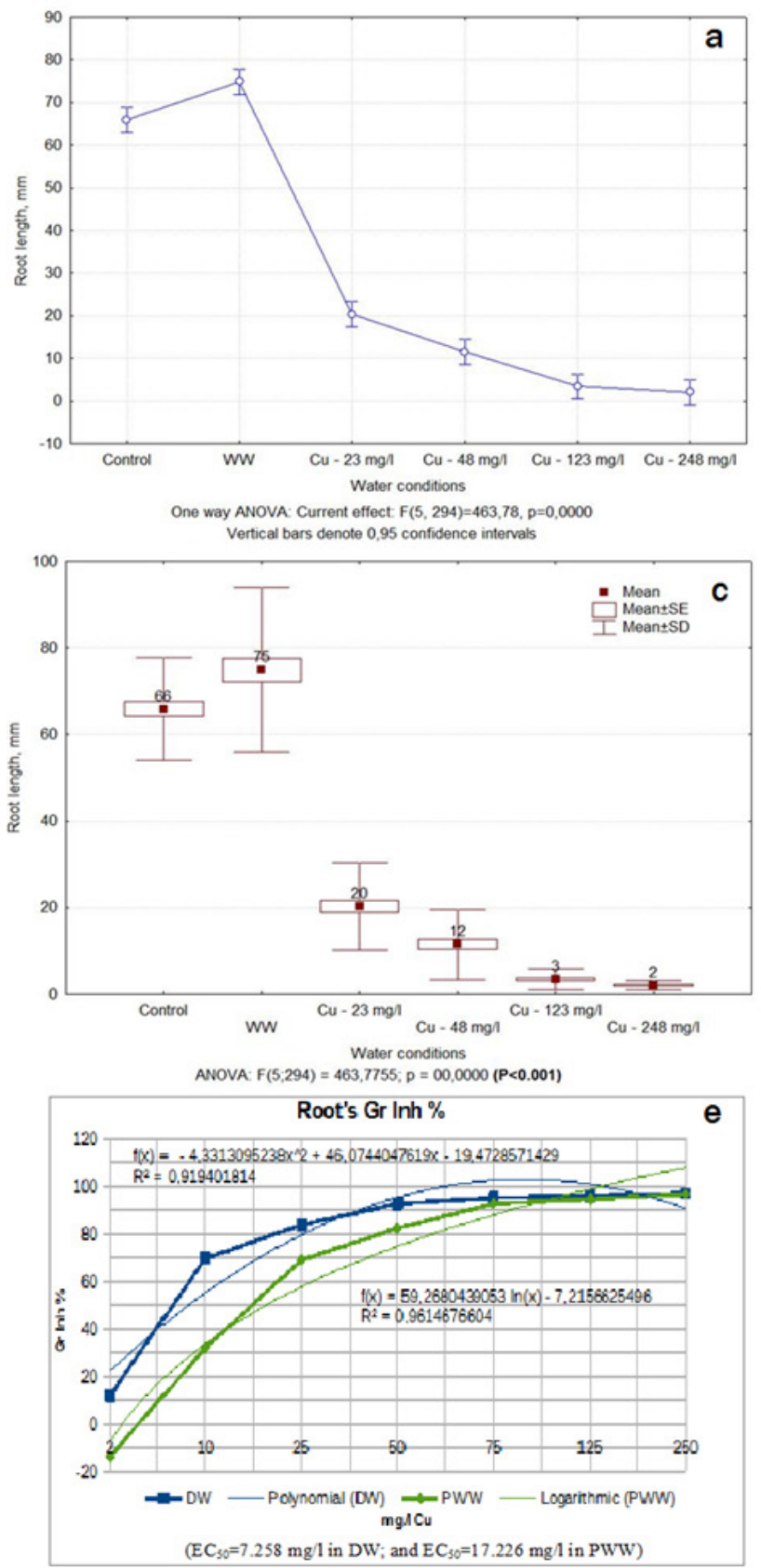

Figures 4 and 5 represent the results of root's and stem's growth inhibition (\%) in presence on different concentrations of $\mathrm{Cu}^{+2}(\mathrm{mg} / \mathrm{l})$ in DW and PIWW. L. sativum $\mathrm{L}$ root's development was affected by $\mathrm{Cu}^{2+}$ metal ions in all concentrations in DW, while in pure PIWW they had a stimulatory effect on the growth of roots and stems (Fig.4 and 5).

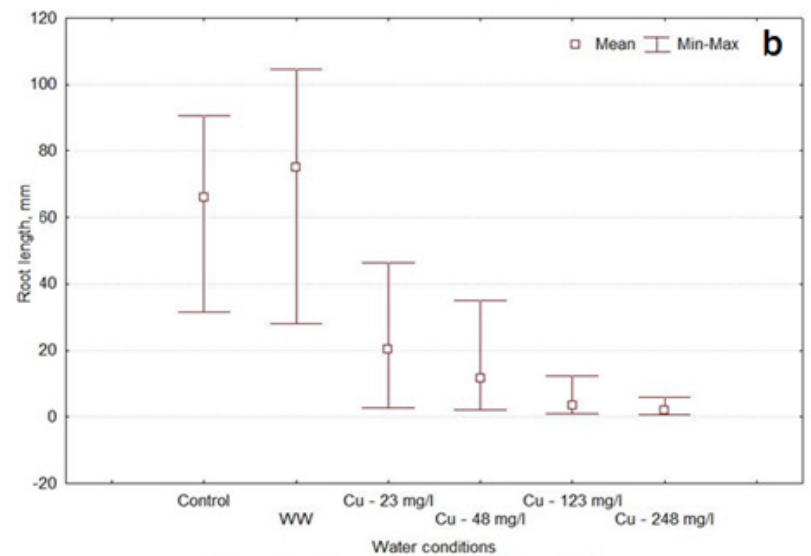

NOVA: $F(5 ; 294)=463,7755 ; P=00.0000(P<0.001)$
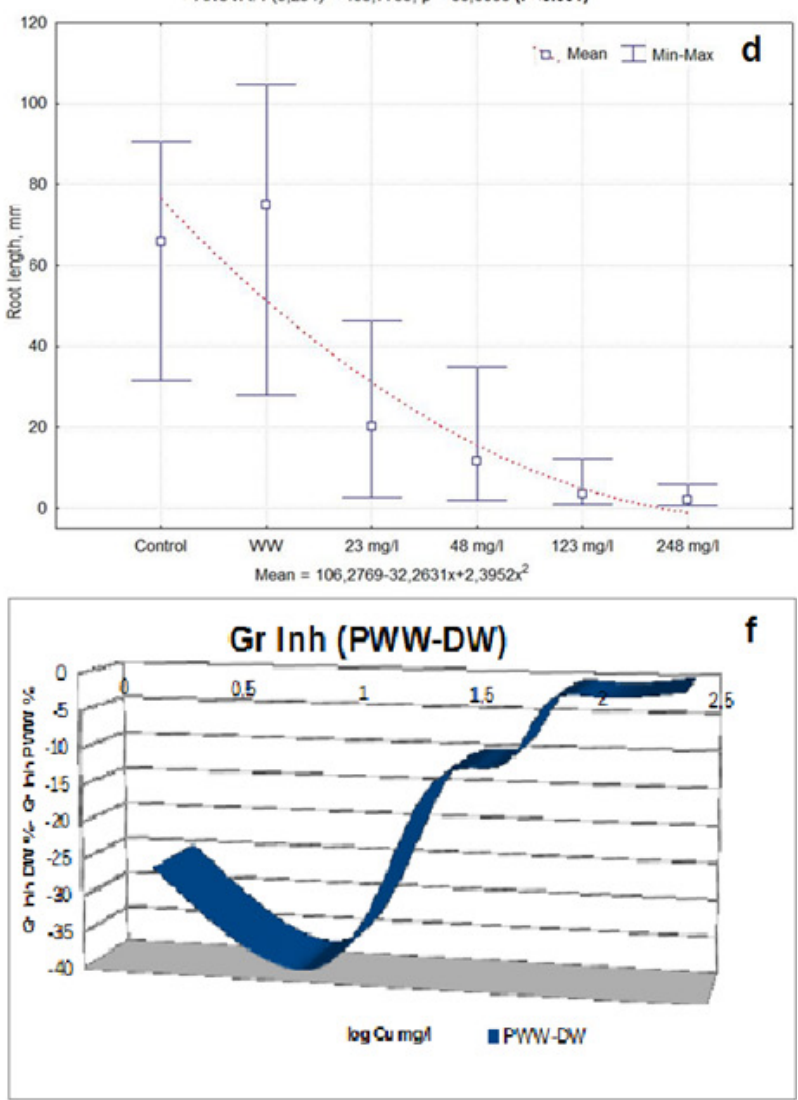

Figure 4. Root's length of Lepidium sativum $L$, Gr Inh $\%$ in dependence of $\mathrm{Cu}^{2+}(\mathrm{mg} / \mathrm{l})$ concentrations in DW (EC $\left.{ }_{50}=7.26 \mathrm{mg} / \mathrm{l}\right)$ and in PIWW $\left(\mathrm{EC}_{50}=17.226 \mathrm{mg} / \mathrm{l}\right)$; (a) Mean of root's length - PIWW stimulated seed development; (b) Mean $\pm \mathrm{SD}$; (c) Mean $\pm \mathrm{SE}$ and SD; (d) Mean=106.2769-32.2631 $\mathrm{x}+2.3952 \mathrm{x}^{2}$ - the regression is negative and polynomic; (e) Growth inhibition of roots (\%) in DW and PIWW (EC $50=7.26 \mathrm{mg} / 1$ in DW; and $\mathrm{EC}_{50}=17.23 \mathrm{mg} / \mathrm{l}$ in PIWW); (f) Substraction of $\mathrm{Cu}^{2+}$ inhibit effects on roots length (PIWW-DW)\%. 

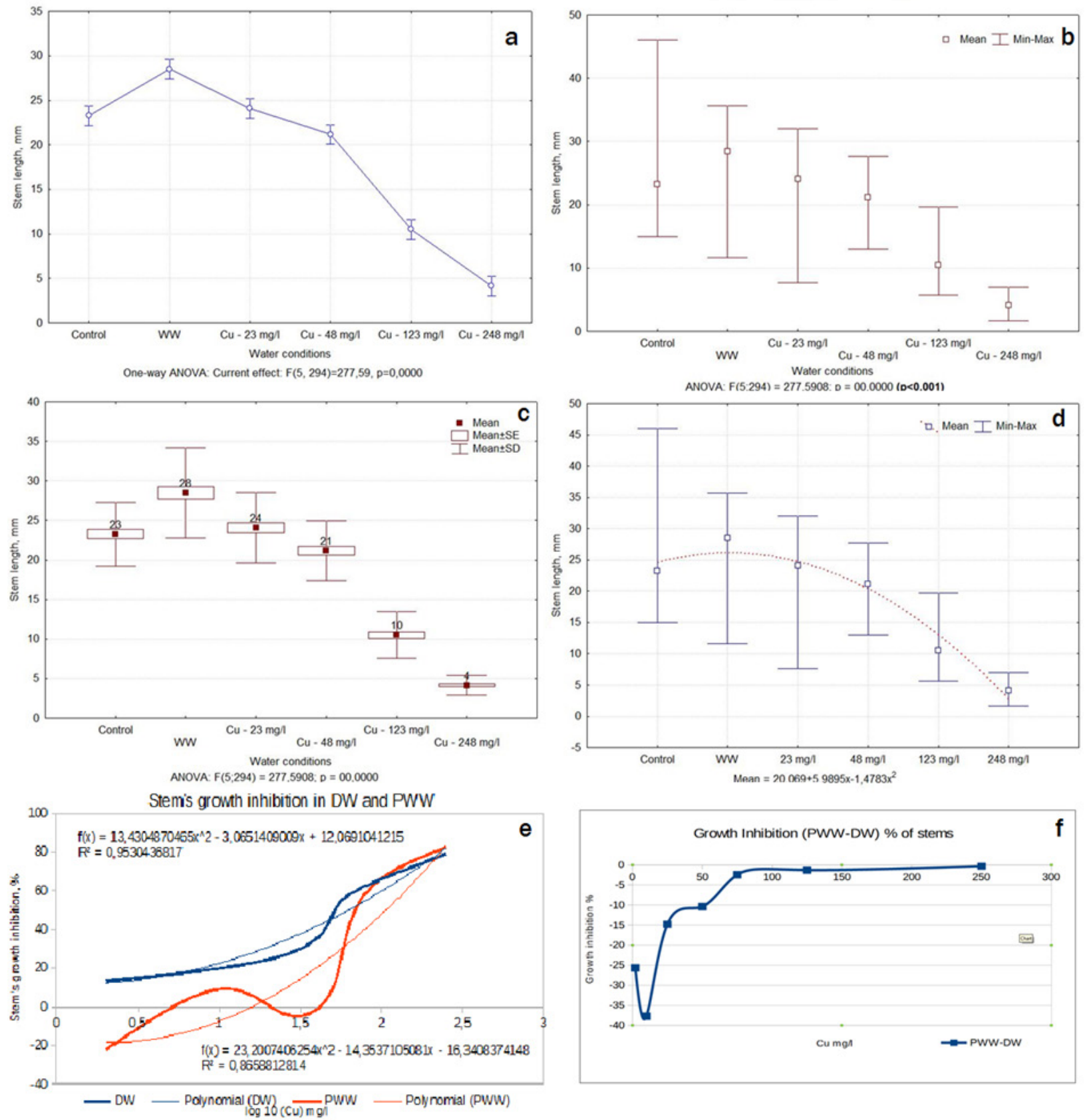

Figure 5. Inhibitory effect on Lepidium sativum $\mathrm{L}$ stem's growth by $\mathrm{Cu}^{2+}$ in increased concentrations (mg/l) of DW $\left(\mathrm{EC}_{50}=54.57 \mathrm{mg} / \mathrm{l}\right)$ and PIWW $\left(\mathrm{EC}_{50}=72.07 \mathrm{mg} / \mathrm{l}\right)$; (a) Mean of variance - pure PIWW has stimulatory effect on stem's growth; (b) Mean $\pm \mathrm{SD}$; (c) Mean $\pm \mathrm{SE}$ and $\mathrm{SD}$; (d) Mean = 20.069+5.9895x-1.4783x2; (e) Growth inhibition of stems (\%) in DW and PIWW; (f) ) Substraction of $\mathrm{Cu}^{2+}$ inhibit effects on stem's length (PIWW-DW)\%.

The root's growth was inhibited by $\mathrm{Cu}^{2+}$ ions in the medium, the trend was polynomic with correlation coefficient $\mathrm{R}^{2}=0.91$ in $\mathrm{DW}$, and logarithmic in PIWW with $\mathrm{R}^{2}=0.96 .50 \%$ inhibition of root's growth appeared in two different ranges for the both water samples, in DW $\mathrm{EC}_{50}=7.26 \mathrm{mg} / 1$ of copper ions, while in PIWW that concentration was $\mathrm{EC}_{50}=17.23 \mathrm{mg} / 1 \quad \mathrm{Cu}^{+2}$ (Fig.5e). Perhaps the impurities in waste water form ligand compounds with copper cations that reduced their bioavailability, and respectively their toxicity. In field studies of ecology and chemistry of upland streams, it has been discovered that copper tends to form organic complexation [10].

The stem's growth of $L$. sativum L. was inhibited with the increasing of $\mathrm{Cu}^{2+}$ ions concentration in the solutions (Table 4$)$, the trends were polynomics $\mathrm{f}(\mathrm{x})=13.43 \times 2-$ $3.085 \mathrm{x}+12.069$ with $\mathrm{R}^{2}=0.95$ in DW and $\mathrm{f}(\mathrm{x})=23.2 \times 2-$ $14.36 \mathrm{x}+16.34$ in PIWW with correlation coefficient $\mathrm{R}^{2}=0.86$. The calculated $\mathrm{EC}_{50}$ for $\mathrm{DW}$ was $\mathrm{EC}_{50}=54.57$ $\mathrm{mg} / \mathrm{l} \mathrm{Cu}{ }^{+2}$ and in PIWW EC $50=72.07 \mathrm{mg} / 1 \mathrm{Cu}^{+2}$ (Fig.5e). The PIWW reduced the toxicity of $\mathrm{Cu}^{+2}$ manifested as mitigating the inhibition of growth (Fig. 5f). 
The pure PIWW that contains low concentration of copper ions $(2 \mathrm{mg} / \mathrm{l})$ stimulated the stem's growth with $22.29 \%$ (Table 4; Fig. 5a).

\section{Discussion}

\subsection{Toxicity of PIWW - Dose-Response Curve}

Acute toxicity test involves estimation of $\mathrm{LC}_{50}$ which is the concentration that proved to be lethal causing 50\% death of the tested organisms. The calculated $\mathrm{LC}_{50}$ for Pseudoraspora parva in dependence on PIWW dilution and based on probit linear regression was 0.13 of PIWW dilution, or it is approximately $8 x$ (7.69) times dilution of purified waste water. The obtained negative regression correlated well with the observed data with coefficient $\mathrm{R}^{2}=0.965$ (Fig. $3 \mathrm{a}$ ). The calculated $\mathrm{LC}_{50}$ based on mortality (\%) of topmouth gudgeon to logarithmic PIWW dilution (Fig.3b) showed similar result at 8x (7.82) times dilution of PIWW, and carried out $50 \%$ mortality of Pseudoraspora parva, with $\mathrm{R}^{2}=0.959$. Therefore, $\mathrm{LC}_{50}$ toxic effect appears in dilutions of PIWW less than 10 times, closed to 8 times.

Probit analysis is commonly used in toxicology to determine the relative toxicity of chemicals to living organisms [44]. Whenever, a chemical substance was administered to a biological system, different types of interactions occurred leading to series of responses [2]. In most studies with the same toxicant and species, variations in toxicity values were frequently observed [44], due to the minor differences in the experiment, environmental conditions, water quality, weight, age, and gender of the fish [7, 45, 46].

Nowadays, probit analysis is still the preferred statistical method in understanding dose-response relationships in acute toxicity analyses and for evaluation of $\operatorname{LC}_{50}[35,44]$.

\subsection{Toxicity of $\mathrm{Cu}^{+2}\left(\mathrm{CuSO}_{4}\right)$ in DW - Dose-Response Curve}

The most bioavailable and therefore most toxic form of copper is the $\mathrm{Cu}^{+2}$ - cupric ion [4, 18, 49, 57]. The toxicity of copper to aquatic life related primarily to the activity of the cupric $\left(\mathrm{Cu}^{2+}\right)$ ion, and possibly to some of the hydroxy complexes [5, 17, 33, 49, 52, and 54]. Information on the relationship of metal speciation to chronic metal toxicity is lacking, but data from acute toxicity experiments indicate that cupric ion is the copper species most toxic to fish $[4,15$, 18, and 49]. The copper toxicity to Thalassiosira pseudonana has been found that is related to cupric ion activity and not to total copper concentration [60].

The obtained dose-respond curves of roots and stems growth in dependence of increased copper concentration in DW are polynomic (Fig. 4e, 5e). There were no good simple linear regression, but based on similar results obtained by other authors, we came to the conclusion that
$\mathrm{Cu}$ and $\mathrm{Pb}$ are not significant predictors in the context of the regressions. Despite the fact that they are significant stressors, there were no apparent effects seen from the simple linear regressions [10].

\subsection{Mixed Toxicity - Dose-Response Curve}

Usually the toxic effect is expressed as $\mathrm{LC}_{50}$ values for mortality and $\mathrm{EC}_{50}$ values for inhibition of growth [27]. Many outcomes of toxicity and ecotoxicity examinations using the same toxicant and test organism differ in $\mathrm{LC}_{50}$ and $\mathrm{EC}_{50}$ values $[27,44]$. Even at low concentrations 2 $\mathrm{mg} / \mathrm{l} \mathrm{Cu}$ introduced as $\mathrm{CuSO}_{4}$ modify the growth rate of unicellular algae and their photosynthetic rates; and a better growth rate was obtained by addition of chelators to the solution [58]. The organic chelators as EDTA, humic acids, glutamic acid, waste-water and detergents decreased $\mathrm{Cu}^{+2}$ bioavailability and hence its toxicity [9]. The obtained dose-response curves of root's and stem's growth inhibition confirmed that PIWW minimize the negative effect of $\mathrm{Cu}^{+2}$ (Table 4; Fig. 4f and 5f).

Copper naturally occurs in waters as divalent cupric ion in free or complexed forms [16]. Not all species of a given metal possess the same toxicity [37]. Toxicity of copper depends on the physicochemical form of the metal, and the organic substances are able to detoxify and complex copper [30]. In unpolluted water copper exist as copper carbonate [16]. In waste water free ion concentrations are lower, because the metal is complexed with dissolved ligands, or possibly bound to colloidal particles $[10,16]$. Under normal conditions, most of the copper in solution is in complexed form, as both organic and inorganic ligands complex copper [16]. Copper express great tendency to form complexes with dissolved organic matter (DOM), the tendency of the metal ions to be complexed increases in the order $\mathrm{Zn}<\mathrm{Cd}<\mathrm{Ni}<\mathrm{Pb}<\mathrm{Cu}$. Nevertheless, in natural water with DOM, copper is present mostly in organically complexed forms with biotic ligand, and therefor has reduced bioavailability and toxicity effect (Fig. 6; [10, 16]).

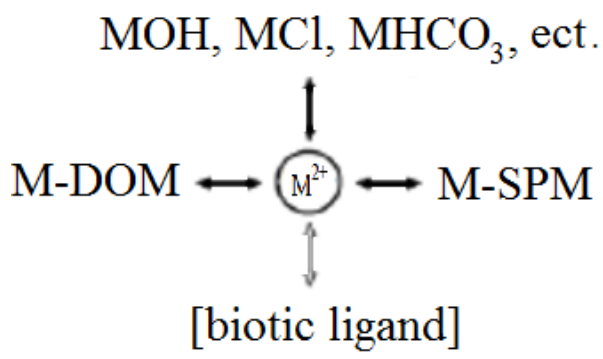

Figure 6. A schematic diagram of metal speciation, including binding to a 'biotic ligand'. DOM - dissolved organic matter, SPM - suspended particulate matter [10]

In polluted waters, complexes of copper with organic material will prevail [16]. The presence of a free cupric ion in eutrophic waters is generally low and may be less than 
$1 \%$, where complexes predominate. The cupric ion is highly reactive and forms moderate to strong complexes and precipitates with many inorganic and organic constituents (carbonate, phosphate, amino acids, and humate). Most organic and inorganic copper complexes and precipitates appear to be much less toxic than free cupric ion and tend to reduce toxicity attributable to total copper concentration [4, 13, and 16]. Williams (1969) found that 5 to $25 \%$ of the total copper concentrations are associated with organic matter [68], while Batley and Florence (1976) recorded 6 to $40 \%$ of $\mathrm{Cu}^{2+}$ associated with DOM [11]. Several types of organic compounds can bind $\mathrm{Cu}$ ions and thus to reduce its toxicity [59]. This greatly complicates the interpretation and application of available toxicity data, because the proportion of free cupric ion presence is highly variable and is difficult to be measured with except under laboratory conditions $[16,26]$.

Toxicity tests have been conducted on copper with a wide range of freshwater plants and the sensitivities are similar to those of animals [25].

\section{Conclusions}

Perhaps, the purified industrial waste water contains detergents up to the maximum acceptable toxicant concentration (MATC). Although the monitored toxicants concentrations were in limits, the fish mortality was nearly $100 \%$ for all variants of the first scheme of testing.

The toxic effect of copper ions were reduced in PIWW perhaps due to the changes in the bioavailability modified under the influence of other impurities, or masked by the influence of detergents. Complexing effects of the test media and a lack of good analytical data make interpretation and application of results difficult.

\section{Acknowledgements}

We are very grateful to Sofia Med Company that allows us to make investigation with their purified industrial waste water to reveal the eventual toxicity that can cause harm to the environment and on biota.

\section{REFERENCES}

[1] Abel P. D., 1974. Toxicity of synthetic detergents to fish and aquatic invertebrates. Fish Biology. Volume 6, Issue 3. May 1974. p. 279-298.

[2] Akhila, J.S., Deepa, S., Alwar, M.C., 2007. Acute toxicity studies and determination of median lethal dose. Current science, 93(7):917-920.

[3] Alexander B., D. J. Browse, S. J. Reading I., S. Benjamin, 1999. A simple and accurate mathematical method for calculation of the $\mathrm{EC}_{50}$. Journal of Pharmacological and Toxicological Methods. Volume 41, Issues 2-3, April-June 1999 , p. 55-58.

[4] Andrew, R.W., 1976. Toxicity relationships to copper forms in natural waters. In: R.W. Andrew, et al. (eds.), Toxicity to Biota of Metal Forms in Natural Water. International Joint Commission, Windsor, Ontario, Canada. p. 127-143.

[5] Andrew, R.W., Biesinger K.E., Glass G.E., 1977. Effects of inorganic complexing on toxicity of copper to Daphnia magna. Water Res. 11: 309-315.

[6] ATSDR (Agency for Toxic Substances and Disease Registry)., 1990. Toxicological Profile for Copper. US Public Health Service, Atlanta, Georgia. TP-90-08. pp. 143.

[7] Ayuba, V.O., Ofojekwu, P.C., 2002. Acute toxicity of the root extract of Jimson's Weed: Datura innoxia to the African catfish (Clarias gariepinus) fingerlings. Journal of Aquatic Science, 17(2): 131 - 133.

[8] Balistrieri, LS, RR Seal II, NM Piatak, B Paul., 2007. Assessing the concentration, speciation, and toxicity of dissolved metals during mixing of acid-mine drainage and ambient river water downstream of the Elizabeth Copper Mine, Vermont, USA. Applied Geochemistry 22 (2007) 930-952.

[9] Barelli, M., 1975. Etude des pollutions chimiques au moyen de deux chaînes trophiques marines. Application aux phénomènes de concentration de polluants métalliques, chrome, cuivre, zinc, mercure, plomb, à travers les organismes marins, Thesis, Université de Nice 1975. 130 pp.

[10] Bass J.A.B., R. Blust, R.T. Clarke, T.A. Corbin, W. Davison, K.A.C. de Schamphelaere, C.R. Janssen, E.J.J. Kalis, M.G. Kelly, N.T. Kneebone, A.J. Lawlor, S. Lofts, E.J.M. Temminghoff, S.A. Thacker, E. Tipping, C.D. Vincent, K.W. Warnken, H. Zhang., 2008. Environmental Quality Standards for trace metals in the aquatic environment Science. Report - SC030194. ISBN: 978-1-84432-887-1. p.190.

[11] Batley G. E., Florence T. M., 1976. Determination of the chemical forms of dissolved cadmium, lead and copper in seawater. Mar. Chem. 4:347-63.

[12] Boadi K.O., Kuitunen M., 2002. Urban waste pollution in the Korle Lagoon, Accra, Ghana. The Environmentalist, 22, p. 301-309.

[13] Borgmann, U. and K.M. Ralph., 1983. Complexation and toxicity of copper and the free metal bioassay cechnigue. Water Res. 17: 1697.

[14] Bulgarian State Standard, BSS., 1985. Seed. Rules for sampling and methods for determining the qualities for sowing. Ministry of Agriculture, Sofia, p. 601.

[15] Calamari D., Roberto Marchetti, 1973. The toxicity of mixtures of metals and surfactants to rainbow trout (Salmo gairdneri rich.). Water Research, Volume 7, Issue 10, October 1973, p. 1453-1464.

[16] Callahan, M.A., Slimak M.W, Gabel N.W., 1979. Water-related environmental fate of 129 priority pollutants. Vol. I. Introduction and Technical Background, Metals and 
Inorganics, Pesticides and PCBs. EPA-440/4-79-029a. National Technical Information Service, Springfield, Virginia.p.132-150.

[17] Chakoumakos, C., Russo R, Thurston R., 1979. The toxicicy of copper to cutthroat trout (Salmo clarki) under different conditions of alkalinity, $\mathrm{pH}$, and hardness. Environ. Sci. Technol. 13: 213.

[18] Chapman, G.A., J.K. McCrady., 1977. Copper toxicity: a question of form. In: Recent Advances in Fish Toxicology. U.S. EPA Ecol. Res. Servo EPA-600j3-77-085. pp. 132-151.

[19] Crommentuijn, T., Polder, M.D., Van de Plassche, E.J., 1997. Maximum Permissible Concentrations and Negligible Concentrations for Metals. Taking Background Concentrations into Account. RIVM Report no. 601501001. National Institute of Public Health and the Environment, Bilthoven, the Netherlands. pp.260.

[20] Davis A.P., M. Shokouhian S. Ni., 2001. Loading estimates of lead, copper, cadmium, and zinc in urban runoff from specific sources. Chemosphere. 44:997-1009.

[21] Davis, RA, AT Welty, J Borrego, JA Morales, JG Pendon, JG Ryan., 2000. Rio Tinto estuary (Spain): 5000 years of pollution. Environmental Geology 39(10): 1107-1116.

[22] De Schamphelaere, K.A.C., Janssen, C.R., 2004. Bioavailability and chronic toxicity of zinc to juvenile rainbow trout (Oncorhynchus mykiss): comparison with other fish species and development of a biotic ligand model. Environmental Science \& Technology, 38(23), 6201-6209.

[23] Demichela, M., Maschio, G., Milazzo, M.F., Salzano, E., 2013. Vulnerability Assessment for Human Targets due to Ash Fallout From Mt. Etna. Chemical Engineering Transactions, 23: $445-450$.

[24] Dineva S.B., 2016. Main Pollutants of Food Raw Materials and Products. on line: ISBN 978-954-9999-99-0. pp.157.

[25] Eisler, R., 2000. Handbook of chemical risk assessment: health hazards to humans, plants and animals. Volume 1: Metals. Lewis Publishers, New York.

[26] EPA, 1985. Ambient aquatic life water quality criteria for copper -1984. EPA 440/5-84-03. pp.

[27] Fargašova A., 1996. Comparative Study of Ecotoxicological Effect of Triorganotin Compounds on Various Biological Subjects. Ecotoxicology and Environmental Safety 36, 38-42 (1997) ARTICLE NO. ES961483.

[28] Finney, D. J., Stevens, W. L., 1948. "A table for the calculation of working probits and weights in probit analysis." Biometrika, 35(1-2): 191-201.

[29] Finney, D. J., Ed., 1952. Probit Analysis. Cambridge, England, Cambridge University Press. p.

[30] Gnassia-Barelli M., M. Romeo, F. Laumond, D. Pesando, 1978. Experimental studies on the relationship between natural copper complexes and their toxicity to phytoplankton. Marine Biology. March 1978, Volume 47, Issue 1, pp 15-19.

[31] Heijerick, D.G., De Schamphelaere, K.A.C., Janssen, C.R., 2002. Predicting acute zinc toxicity for Daphnia magna as a function of key water chemistry characteristics: development and validation of a biotic ligand model. Environmental Toxicology \& Chemistry, 21(6), 13091315.

[32] Horne MT, Dunson WA., 1995. Effects of Low pH, Metals, and Water Hardness on Larval Amphibians. Archives of Environmental Contamination and Toxicology, 29: 500-505.

[33] Howarch, R.S., J.B. Sprague, 1978. Copper lethality co rainbow trout in waters of various hardness and $\mathrm{pH}$. Water Res. 12: 455.

[34] Kabata-Pendias A., Pendias H., 1992. Trace Elements in Soils and Plants, 2nd ed. CRC Press, Boca Raton. 365p.

[35] Kim, V., 2008. Probit Analysis. Available on http://userwww.sfsu.edu/efc/classes/biol710/probit/Probit Analysis, pdf, pp. 8

[36] Lee, L., Helsel D., 2005. Baseline models of trace elements in major aquifers of the United States. Applied Geochemistry 20(8): 1560-1570.

[37] Lind D., Th. Halpern, Mark D. Johnson, 1978. The toxicity of heavy metals, beneficiation reagents and hydrogen ion to aquatic organisms. http://www.leg.state.mn.us/lrl/lrl.asp. p.189.

[38] Lyubenova M., S. Boteva, 2016. Biotests in Ecotoxicology: Current Practice and Problems. Toxicology - New Aspects to This Scientific Conundrum. Chapter 7. http://dx.doi.org/10.5772/64776

[39] Lyubenova M., R. Kalchev, 2009. Ecotoxicology. Small practicum. Sofia, An-Di Publishing House, 333 p. (in Bulgarian).

[40] Nagajyoti P. C., K. D. Lee, T. V. M. Sreekanth, 2010. Heavy metals, occurrence and toxicity for plants: a review. Environ Chem Lett (2010) 8:199-216. DOI 10.1007/s10311-010-0297-8.

[41] National Academy of Science (NAS), 1986. Health effects of excess copper. Chapter 5. In Copper in drinking water. National Academy Press. Washington DC.

[42] Nordberg, GF, BA Fowler, M Nordberg, and LT Friberg. 2007. Handbook in the toxicology of metals. Elsevier. NY.

[43] Nriagu, J. O. 1979. Copper in the atmosphere and precipitation. In J.O. Nriagu (Editor) Copper in the Environment. Part 1: ecological cycling. John Wiley, NY. p. 45-75.

[44] Okomoda V, Solomon, S. G., Ataguba, G. A., Ayuba, V. O., Asuwaju, F. P. 2013. Acute toxicity test in aquaculture: a review. Proceedings of the 28th Annual Conference of Fisheries Society of Nigeria. Ajuji Best Western Hotel, Joseph Gomwalk Rd., Abuja Nov. 25-29, 2013, p.171 -175.

[45] Okomoda, V. T., Ataguba, G. A. and Ayuba, V. O. 2013. Hematological Response of Clarias gariepinus Fingerlings Exposed to Acute Concentrations of Sunsate ${ }^{\circledR}$, Journal of Stress Physiology \& Biochemistry, ISSN 1997-0838, Vol. 9 No. 2 2013, pp: 271-278.

[46] Onusiriuka, B.C., 2002. Effect of sub-lethal concentration of formalin on weight gain in the African cat fish, Clarias gariepinus (Teugels) Journal of Aquatic Sciences, 17: 66 68 
[47] Oronsaye, J.A.O., Ogbebo, P. E., 1997. Acute toxicity of copper to Clarias gariepinus in soft water. Journal of Aquatic Sciences 10: 19-23.

[48] Oyewo E.O., 1998. Industrial Sources and Distribution of Heavy Metals in Lagos Lagoon and their Biological Effects on Estuarine animals. Ph.D. Thesis Department of Marine Science. University of Lagos, $274 \mathrm{pp}$.

[49] Pagenkopf, G.K., R.C. Russo, R.V. Thurston. 1974. Effect of complexation on toxicity of copper to fishes. J. Fish. Res. Bd. Can. 31:462-465.

[50] Pattusamy V., N. Nandini, K. Bheemappa, 2013. Detergent and Sewage Phosphates entering into Lake Ecosystem and Its Impact on Aquatic Environment. International Journal of Advanced Research (2013), Volume 1, Issue 3, 129-133.

[51] Pavel V. L., Sobariu D. L, Diaconu M., Stătescu F., Gavrilescu M., 2013. Effects of Heavy Metals on Lepidium sativum Germination and Growth. Environmental Engineering and Management Journal. "Gheorghe Asachi" Technical University of Iasi, Romania. April 2013, Vol.12, No. 4, 727-733.

[52] Petersen, R., 1982. Influence of copper and zinc on the growth of a freshwater algae, Scenedesmus quadricauda: the significance of speciation. Environ. Sci. Technol. 16: 443.

[53] Project No 43799, 2013. Project No. 43799 of the European Bank for reconstruction and development. Extension of long-term loan to Sofia Med S.A. p.21.

[54] Rueter, J.G., 1983. Alkaline phosphacase inhibition by copper: implications to phosphorus nutrition and use as a biochemical marker of toxicity. Limno I. Oceanogr. 28: 743.

[55] Runkel, R.L., K.E. Bencala, B.A. Kimball, K. Walton-Day, P.L. Verplanck, 2009. A comparison of pre- and post-remediation water quality, Mineral Creek, Colorado. Hydrological Processes 23: 3319-3333.

[56] Sansalone, J.J., S.G. Buchberger, ASCE Members. 1997. Partitioning and first flush of metals in urban road way storm water. Journal of Environmental Engineering 123: 134-143.
[57] Solomon F., 2009. Impacts of Copper on Aquatic Ecosystems and Human Health. MINING.com January 2009. p.25-28.

[58] Steeman Nielsen, E., H. Bruun Laursen, 1976. Effect of $\mathrm{CuSO}_{4}$ on the photosynthetic rate of phytoplankton in four Danish lakes. Oikos 27, 239-242.

[59] Stemmann Nielsen, E., L. Kamp-Nielsen 1970. Influence of deleterious concentrations of copper on the growth of Chlorella pyrenoidosa Physiol. Plant 23:828-840.

[60] Sunda W., Guillard R K L. 1976. The relationship between cupric ion activity and the toxicity of copper to phytoplankton. I. Mar. Res. 34:511-29.

[61] Tchounwou P. B., C. G. Yedjou, A K Patlolla, and D. J Sutton, 2014. Heavy Metals Toxicity and the Environment. PMC 4144270. doi: 10.1007/978-3-7643-8340-4 6. EXS. 2012; 101: 133-164.

[62] US EPA, 1993. Wildlife Exposure Factor Handbook. Vol. 1 EPA/600/R-93/187. pp.572.

[63] Vinot I., Pihan J.C., 2005. Circulation of copper in the biotic compartments of a freshwater dammed reservoir. Environmental Pollution, Volume 133, Issue 1, January 2005, p.169-182.

[64] Vymazal J., 1995. Algae and Element Cycling in Wetlands. Lewis Pub., Boca Raton. pp. 689.

[65] Ware G., 1983. Pesticides, Theory and Application. W.H Freeman, New York. pp. 308.

[66] WHO. World Health Organization. Switzerland: Geneva; 1996. Trace Elements in Human Nutrition and Health. p.360.

[67] Zamzow, K.L., 2011. Investigations of surface water quality in the Nushagak, Kvichak, and Chulitna watersheds, Southwest Alaska 2009-2010. Report prepared for The Nature Conservancy, Anchorage, AK. p. 42.

[68] Williams, P. M., 1969. The association of copper with dissolved organic matter in seawater, Limnol. and Oceanogr. 14, 156. 